\title{
Pre-impaired Fasting Glucose State Is A Risk Factr for Endothelial Dysfunction Flow-mediated Dilation Japan (FMD-J) Study
}

\author{
Takayuki Yamaji \\ "Hiroshima Daigaku" \\ Takahiro Harada \\ "Hiroshima Daigaku" \\ Yu Hashimoto \\ "Hiroshima Daigaku" \\ Yuji Takaeko \\ "Hiroshima Daigaku" \\ Masato Kajikawa \\ "Hiroshima Daigaku" \\ Yasuki Kihara \\ "Hiroshima Daigaku" \\ Eisuke Hida \\ Osaka Daigaku \\ Kazuaki Chayama \\ "Hiroshima Daigaku" \\ Chikara Goto \\ "Hiroshima Daigaku" \\ Yiming Han \\ "Hiroshima Daigaku" \\ Farina Mohamad Yusoff \\ "Hiroshima Daigaku" \\ Shinji Kishimoto \\ "Hiroshima Daigaku" \\ Tatsuya Maruhashi \\ "Hiroshima Daigaku" \\ Ayumu Nakashima \\ "Hiroshima Daigaku" \\ Yukihito Higashi ( $\square$ yhigashi@hiroshima-u.ac.jp) \\ Hiroshima university https://orcid.org/0000-0001-5813-3672
}

\section{Original investigation}

Keywords: fasting blood glucose, high normal blood glucose, impaired fasting blood glucose, endothelial function, flow-mediated vasodilation

Posted Date: May 29th, 2020

DOI: https://doi.org/10.21203/rs.3.rs-30721/v1

License: @ (i) This work is licensed under a Creative Commons Attribution 4.0 International License. Read Full License 


\section{Abstract \\ Background}

There is little information on the relationships of fasting blood glucose (FBG) including high normal blood glucose and impaired fasting glucose (IFG) with endothelial function. The purpose of this study was to evaluate the relationship between FBG level and flow-mediated vasodilation (FMD) in detail using a large sample size.

\section{Methods}

This study was a cross-sectional study. We measured FMD in 7265 subjects at 31 general hospitals. The subjects were divided into four groups based on FBG levels: $<5.55 \mathrm{mmol} / \mathrm{L}, 5.55-6.05 \mathrm{mmol} / \mathrm{L}, 6.11-6.94 \mathrm{mmol} / \mathrm{L}$, and $\geq 6.99 \mathrm{mmol} / \mathrm{L}$ or known type 2 diabetes. The subjects were also divided into six groups based on FBG levels: $<5.00 \mathrm{mmol} / \mathrm{L}, 5.00-5.22 \mathrm{mmol} / \mathrm{L}, 5.27-5.50 \mathrm{mmol} / \mathrm{L}, 5.55-$ $6.05 \mathrm{mmol} / \mathrm{L}, 6.11-6.94 \mathrm{mmol} / \mathrm{L}$, and $\geq 6.99 \mathrm{mmol} / \mathrm{L}$ or known type 2 diabetes.

\section{Results}

FMD decreased in relation to increase in FBG level. There was a significant difference in FMD between the FBG of $<5.55 \mathrm{mmol} / \mathrm{L} \mathrm{group}$ and the other three groups $(6.7 \pm 3.1 \%$ vs. $5.9 \pm 2.8 \%, 5.7 \pm 3.1 \%$, and $5.1 \pm 2.6 \% ; p<0.001$, respectively). After adjustment for confounding factors, the odds of having the lowest quartile of FMD was significantly higher in the FBG of $5.27-5.50 \mathrm{mmol} / \mathrm{L}, 5.55-6.05 \mathrm{mmol} / \mathrm{L}$, $6.11-6.94 \mathrm{mmol} / \mathrm{L}$, and $\geq 6.99 \mathrm{mmol} / \mathrm{L}$ or known type 2 diabetes groups than in the $\mathrm{FBG}$ of $<5.00 \mathrm{mmol} / \mathrm{L}$, group.

\section{Conclusions}

These findings suggest that FBG of $5.55-6.05 \mathrm{mmol} / \mathrm{L}$ and FBG of $6.11-6.94 \mathrm{mmol} / \mathrm{L}$ are similarly associated with endothelial dysfunction and that a pre-IFG state (FBG of $5.27-5.50 \mathrm{mmol} / \mathrm{L}$ ) is also a risk for endothelial dysfunction compared with $\mathrm{FBG}$ of < $5.00 \mathrm{mmol} / \mathrm{L}$.

\section{Clinical Trial Registry Information:}

http://www.umin.ac.jp (UMIN000012950, UMIN000012951, UMIN000012952, and UMIN000003409)

\section{Background}

Diabetes is a well-established risk factor for cardiovascular events.[1] It is well known that cardiovascular risk is increased before the onset of diabetes as a state of prediabetes.[2] In the American Diabetes Association (ADA) classification, a fasting blood glucose (FBG) range of 5.55-6.94 mmol/L is categorized as impaired fasting glucose (IFG).[3] However, before 2003, an FBG range of 6.11$6.94 \mathrm{mmol} / \mathrm{L}$ was categorized as IFG in the ADA classification. In World Health Organization criteria, an FBG range of 6.11-6.94 mmol/L is categorized as IFG. In the Japan Diabetes Society criteria, an FBG range of $6.11-6.94 \mathrm{mmol} / \mathrm{L}$ is categorized as prediabetes, and a range of 5.55-6.05 mmol/L is categorized as high normal blood glucose.[4] The definition of IFG differs between countries and eras.

Endothelial dysfunction is known as the first step in the pathogenesis of atherosclerosis and is also known as a marker of cardiovascular events.[5, 6] Measurement of flow-mediated vasodilation (FMD) in the brachial artery is widely used for assessment of endothelial function. FMD is also well known as an independent predictor of cardiovascular events.[7-11] In addition, measurement of FMD is an independent predictor of cardiovascular events in a general population including individuals with diabetes. It has been established that diabetes is associated with endothelial dysfunction.[12-14] However, the relationship between IFG and endothelial function is still controversial. Some investigators have shown that IFG is associated with endothelial dysfunction.[15-18] On the other hand, Henry et al. reported that IFG was not assosiated with endothelial dysfunction.[13]

There has been no study on the detailed relationships of FBG including a normal range of glucose, pre-IFG range, and IFG range with endothelial function. In addition, it remains unclear at what level of FBG has a harmful effect on endothelial function. Therefore, we evaluated the relationship between FBG and endothelial function assessed by FMD in multiple centers using a large sample size. 


\section{Methods \\ Study subjects}

The Flow-mediated Dilation Japan Registry (FMD-J) was a prospective multicenter registry that was established between April 1, 2010 and August 31, 2018 at 31 institutes in Japan with the aim of determining the usefulness of FMD measurement. All of the subjects had an obligation to undergo health screening every year under the regulations of the society-managed health insurance union in Japan. The design of the FMD-J study has been described in detail.[19] We excluded the following subjects: subjects with severe chronic heart failure (New York Heart Association level of more than III), subjects with severe valvular disease, arrhythmia receiving treatment, or malignancy, subjects taking steroids, nonsteroidal anti-inflammatory drugs or immunosuppressive drugs, subjects over 80 years of age, subjects on dialysis or with end-stage chronic kidney disease, and subjects without information on fasting blood glucose. Finally, we enrolled 7265 subjects in this study. Hypertension was defined as the use of antihypertensive drugs or systolic blood pressure of more than $140 \mathrm{~mm} \mathrm{Hg}$ or diastolic blood pressure of more than $90 \mathrm{~mm} \mathrm{Hg}$ measured in a sitting position on at least 3 occasions. Dyslipidemia was defined according to the third report of the National Cholesterol Education Program.[20] Type 2 diabetes was defined according to the American Diabetes Association recommendation.[21] Smokers were defined as those who were current smokers. Cardiovascular disease was defined as coronary heart disease and cerebrovascular disease. Coronary heart disease included angina pectoris, prior myocardial infarction, and unstable angina. Cerebrovascular disease included ischemic stroke, hemorrhagic stroke, and transient ischemic attack. The Ethics Committee of Hiroshima University approved the study protocol. Written informed consent for participation in this study was obtained from all participants.

\section{Study Protocol}

We measured the vascular response to reactive hyperemia in the brachial artery for assessment of endothelium-dependent FMD. The patients fasted overnight and abstained from alcohol, smoking, caffeine and antioxidant vitamins for at least 12 hours before the study. The participants were kept in the supine position in a quiet, dark, air-conditioned room (constant temperature of $22{ }^{\circ} \mathrm{C}$ to $25^{\circ} \mathrm{C}$ ) throughout the study. A 23-gauge polyethylene catheter was inserted into the deep antecubital vein to obtain blood samples for measurements including measurement of FBG. After maintaining the supine position for 30 minutes, FMD was measured. The observers were blind to the form of examination.

We investigated the relationship between FBG level and endothelial function assessed by measurement of FMD. First, the subjects were divided into four groups based on their FBG levels: $<5.55 \mathrm{mmol} / \mathrm{L}, 5.55-6.05 \mathrm{mmol} / \mathrm{L}, 6.11-6.94 \mathrm{mmol} / \mathrm{L}$, and $\geq 6.99 \mathrm{mmol} / \mathrm{L}$ or $\mathrm{known}$ type 2 diabetes. Multivariate regression analysis was performed to identify independent variables associated with endothelial function. Next, the subjects were divided into six groups based on their FBG levels: $<5.55 \mathrm{mmol} / \mathrm{L}(<5.00 \mathrm{mmol} / \mathrm{L}, 5.00-5.22 \mathrm{mmol} / \mathrm{L}$ and $5.27-$ $5.50 \mathrm{mmol} / \mathrm{L}), 5.55-6.05 \mathrm{mmol} / \mathrm{L}, 6.11-6.94 \mathrm{mmol} / \mathrm{L}$, and $\geq 6.99 \mathrm{mmol} / \mathrm{L}$ or known type 2 diabetes.

\section{Measurement Of FMD}

A high-resolution linear artery transducer was coupled to computer-assisted analysis software (UNEXEF18G, UNEX Co., Nagoya, Japan) that used an automated edge detection system for measurement of the brachial artery diameter. [22] A blood pressure cuff was placed around the forearm of each subjects. The brachial artery was scanned longitudinally 5 to $10 \mathrm{~cm}$ above the elbow. When the clearest Bmode image of the anterior and posterior intimal interfaces between the lumen and vessel wall was obtained, the transducer was held at the same point throughout the scan by using a special probe holder (UNEX Co.) to ensure consistency of the imaging. Depth and gain setting were set to optimize the images of the arterial lumen wall interface. When the tracking gate was placed on the intima, the artery diameter was automatically tracked, and the waveform of diameter changes over the cardiac cycle was displayed in real time using the FMD mode of the tracking system. This allowed the ultrasound images to be optimized at the start of the scan and the transducer position to be adjusted immediately for optimal tracking performance throughout the scan. Pulsed Doppler flow was assessed at baseline and during peak hyperemic flow, which was confirmed to occur within 15 seconds after cuff deflation. Blood flow velocity was calculated from the color Doppler data and was displayed as a waveform in real time. Baseline longitudinal images of the artery were acquired for 30 seconds, and then the blood pressure cuff was inflated to $50 \mathrm{~mm} \mathrm{Hg}$ above systolic pressure for 5 minutes. Blood flow volume was calculated by multiplying the Doppler flow velocity (corrected for the angle) by heart rate and vessel cross-sectional area ($r^{2}$ ). Reactive hyperemia was calculated as the maximum percentage increase in flow after cuff deflation compared with baseline flow. The correlation coefficient between FMD analyzed at the core laboratory and participant institutions was $0.84(p<0.001)$.

Page $3 / 16$ 


\section{Statistical analysis}

Results are presented as means \pm SD. All reported probability values were 2 -sided, and a probability value of $<0.05$ was considered statistically significant. Categorical values were compared by means of the chi-square test. Continuous variables were compared by using ANOVA multiple groups. Comparisons between the groups categorized according to FBG levels were carried out using repeated measures ANOVA with Tukey's post hoc test. Univariate linear regression analyses were performed to assess the relationships among the variables. Multivariate regression analyses using Ordinary Least Squares was performed to identify independent variables associated with FMD from the following covariates with $p<0.05$ for inclusion age: body mass index, systolic blood pressure, heart rate, triglycerides, high-density lipoprotein cholesterol, low-density lipoprotein cholesterol, glucose, uric acid, and creatine. Multivariate logistic regression analysis was performed to identify independent variables associated with lower quartiles of FMD $(<4.2 \%)$. Age over 65 years old, gender, obesity (body mass index of 30 or higher), current smoking, presence of hypertension and presence of dyslipidemia were entered into the multivariate logistic regression analysis. All data were processed using JMP Pro. Ver 14.0 software (SAS Institute, Cary, NC, USA)

\section{Results}

\section{Baseline characteristics of the subjects}

The baseline characteristics of the 7265 subjects are summarized in Table 1. The mean age of the subjects was 51 years. The 7265 subjects included 5804 men (79.9\%) and 1461 women (20.1\%). The mean FBG level in the subjects was $5.61 \pm 1.11 \mathrm{mmol} / \mathrm{L}$ and the mean $\mathrm{HbA} 1 \mathrm{c}$ level was $38.33 \pm 7.17 \mathrm{mmol} / \mathrm{mol}(5.7 \pm 0.7 \%)$. Among the subjects, $3188(43.9 \%)$ had hypertension, $3760(51.8 \%)$ had dyslipidemia, 685 (9.4\%) had type 2 diabetes, 689 (9.5\%) had previous cardiovascular disease and 2189 (30.3\%) were current smokers. The mean FMD value was $6.3 \pm 3.1 \%$. 
Table 1

Clinical Characteristics of Patients in Four Groups of FBG Levels

\begin{tabular}{|c|c|c|c|c|c|c|}
\hline Variables & $\begin{array}{l}\text { Total } \\
(n=7265)\end{array}$ & $\begin{array}{l}\text { FBG } \\
<5.55 \\
\mathrm{mmol} / \mathrm{L} \\
(\mathrm{n}=4357)\end{array}$ & $\begin{array}{l}\text { FBG } \\
5.55-6.05 \\
\text { mmol/L } \\
(n=1540)\end{array}$ & $\begin{array}{l}\text { FBG } \\
6.11-6.94 \\
\mathrm{mmol} / \mathrm{L} \\
(n=551)\end{array}$ & $\begin{array}{l}\text { FBG } \\
\geq 6.99 \mathrm{mmol} / \mathrm{L} \\
\text { or } \\
\text { type } 2 \text { diabetes } \\
(n=817)\end{array}$ & $P$ value \\
\hline Age, yr & $51 \pm 10$ & $48 \pm 10$ & $53 \pm 9$ & $54 \pm 8$ & $59 \pm 9$ & $<0.001$ \\
\hline Gender, men/women & $5804 / 1461$ & $3287 / 1070$ & $1356 / 184$ & $492 / 59$ & $669 / 148$ & $<0.001$ \\
\hline Body mass index, kg/m² & $23.5 \pm 3.3$ & $22.8 \pm 3.1$ & $24.1 \pm 3.0$ & $25.0 \pm 3.4$ & $25.3 \pm 3.9$ & $<0.001$ \\
\hline Heart rate, bpm & $64 \pm 10$ & $63 \pm 10$ & $64 \pm 11$ & $65 \pm 10$ & $66 \pm 11$ & $<0.001$ \\
\hline Systolic blood pressure, $\mathrm{mmHg}$ & $127 \pm 16$ & $124 \pm 16$ & $130 \pm 16$ & $132 \pm 16$ & $134 \pm 17$ & $<0.001$ \\
\hline Diastolic blood pressure, $\mathrm{mmHg}$ & $80 \pm 12$ & $78 \pm 12$ & $82 \pm 11$ & $83 \pm 12$ & $81 \pm 11$ & $<0.001$ \\
\hline Total cholesterol, mmol/L & $5.20 \pm 0.88$ & $5.17 \pm 0.83$ & $5.35 \pm 0.88$ & $5.35 \pm 0.93$ & $4.97 \pm 0.96$ & $<0.001$ \\
\hline Triglycerides, mmol/L & $1.45 \pm 1.04$ & $1.31 \pm 0.91$ & $1.57 \pm 1.04$ & $1.73 \pm 1.11$ & $1.73 \pm 1.43$ & $<0.001$ \\
\hline HDL-C, mmol/L & $1.53 \pm 0.41$ & $1.53 \pm 0.41$ & $1.50 \pm 0.39$ & $1.45 \pm 0.39$ & $1.37 \pm 0.39$ & $<0.001$ \\
\hline LDL-C, mmol/L & $3.03 \pm 0.78$ & $3.00 \pm 0.75$ & $3.15 \pm 0.78$ & $3.15 \pm 0.85$ & $2.84 \pm 0.83$ & $<0.001$ \\
\hline Creatinine, $\mu \mathrm{mol} / \mathrm{L}$ & $72.49 \pm 15.03$ & $71.60 \pm 14.14$ & $74.26 \pm 15.03$ & $73.37 \pm 14.14$ & $72.49 \pm 18.56$ & $<0.001$ \\
\hline Uric acid, $\mu \mathrm{mol} / \mathrm{L}$ & $345 \pm 83$ & $333 \pm 83$ & $363 \pm 77$ & $369 \pm 83$ & $345 \pm 83$ & $<0.001$ \\
\hline Fasting blood glucose, mmol/L & $5.61 \pm 1.11$ & $5.05 \pm 0.33$ & $5.77 \pm 0.17$ & $6.38 \pm 0.22$ & $7.72 \pm 2.00$ & $<0.001$ \\
\hline Hemoglobin A1c, \% & $5.7 \pm 0.7$ & $5.4 \pm 0.3$ & $5.6 \pm 0.3$ & $5.8 \pm 0.3$ & $6.9 \pm 1.0$ & $<0.001$ \\
\hline Hemoglobin A1c, mmol/mol & $38.33 \pm 7.17$ & $35.72 \pm 3.17$ & $37.59 \pm 3.43$ & $39.90 \pm 3.57$ & $52.39 \pm 11.17$ & $<0.001$ \\
\hline \multicolumn{7}{|l|}{ Medical history, n (\%) } \\
\hline Hypertension & 3188 (43.9) & $1488(34.2)$ & 763 (49.6) & $306(55.6)$ & $631(77.3)$ & $<0.001$ \\
\hline Dyslipidemia & 3760 (51.8) & 1867 (42.9) & 912 (59.3) & $374(68.0)$ & $607(74.4)$ & $<0.001$ \\
\hline Diabetes mellitus & $685(9.4)$ & 0 & 0 & 0 & $685(83.8)$ & $<0.001$ \\
\hline CVD, n (\%) & $689(9.5)$ & $214(4.9)$ & $137(8.9)$ & $71(12.9)$ & $267(32.7)$ & $<0.001$ \\
\hline Current Smoking, n (\%) & $2189(30.3)$ & $1355(31.2)$ & $456(29.7)$ & $161(29.5)$ & $217(27.2)$ & 0.12 \\
\hline \multicolumn{7}{|l|}{ Medication, n (\%) } \\
\hline Antihypertensive drugs & 2009 (27.7) & $829(19.0)$ & $480(31.2)$ & $200(36.4)$ & $500(61.3)$ & $<0.001$ \\
\hline Lipid lowering drugs & $1116(15.4)$ & $402(9.2)$ & 238 (15.5) & 106 (19.3) & 370 (45.3) & $<0.001$ \\
\hline Anti-diabetic drugs & $489(6.7)$ & $0(0)$ & $0(0)$ & $0(0)$ & $489(60.0)$ & $<0.001$ \\
\hline
\end{tabular}

FBG indicates fasting blood glucose; HDL-C indicates high-density lipoprotein cholesterol; LDL-C, low-density lipoprotein cholesterol; CVD, cardiovascular disease; FMD, flow-mediated vasodilation.

\section{Relationships among FMD, FBG and variables}

Online Table S1 shows univariate relationships among FMD, FBG level and variables. FMD was significantly correlated with age ( $r=-0.31$, $p<0.001)$, body mass index ( $r=-0.19, p<0.001)$, heart rate $(r=0.06, p<0.001)$, systolic blood pressure $(r=-0.15, p<0.001)$, diastolic blood pressure $(r=-0.08, p<0.001)$, total cholesterol $(r=-0.03, p=0.03)$, triglycerides $(r=-0.11, p<0.001)$, high-density lipoprotein cholesterol $(r=$ 
0.08, $p<0.001)$, creatinine $(r=-0.07, p<0.001)$, uric acid $(r=-0.13, p<0.001)$, FBG level $(r=-0.14, p<0.001)(F i g .1)$ and HbA1c level $(r=-0.16$, $p<0.001)$. FBG level was significantly correlated with age $(r=-0.26, p<0.001)$, body mass index $(r=0.23, p<0.001)$, heart rate $(r=0.13$, $p$ $<0.001)$, systolic blood pressure $(r=0.19, p<0.001)$, diastolic blood pressure $(r=0.11, p<0.001)$, triglycerides $(r=0.18, p<0.001)$, highdensity lipoprotein cholesterol $(r=-0.15, p<0.001)$, uric acid $(r=0.06, p<0.001)$, HbA1c level $(r=0.77, p<0.001)$ and FMD $(r=-0.14, p<$ 0.001).

Online Table S2 shows multivariate linear relationships among FMD, FBG level and variables. Multiple linear regression analysis revealed that age $(\beta=-0.23, p<0.001)$, body mass index $(\beta=-0.10, p<0.001)$, heart rate $(\beta=0.09, p<0.001)$, systolic blood pressure $(\beta=-0.04, p=$ $0.001)$, triglycerides $(\beta=-0.04, p=0.001)$, high-lipoprotein cholesterol $(\beta=-0.03, p=0.02)$, uric acid $(\beta=-0.07, p<0.001), F B G(\beta=-0.03, p=$ $0.02)$, antihypertensive drug treatment $(\beta=0.13, p<0.001)$, and current smoking $(\beta=0.07, p<0.001)$ were independent predictors of FMD.

\section{FMD values in four groups of FBG levels}

The baseline characteristics of subjects with FBG of $<5.55 \mathrm{mmol} / \mathrm{L}, 5.55-6.05 \mathrm{mmol} / \mathrm{L}, 6.11-6.94 \mathrm{mmol} / \mathrm{L}$, and $\geq 6.99 \mathrm{mmol} / \mathrm{L}$ or known type 2 diabetes are also summarized in Table 1. There were significant differences in age, gender, body mass index, heart rate, systolic blood pressure, diastolic blood pressure, levels of total cholesterol, triglycerides, high-density lipoprotein cholesterol, low-density lipoprotein cholesterol, creatinine, uric acid, FBG, and $\mathrm{HbA} 1 \mathrm{c}$, prevalences of hypertension, dyslipidemia, and cardiovascular disease, and use of antihypertensive drugs and lipid-lowering drugs among the four groups. Figure 2 shows FMD values in the four groups. FMD values were $6.7 \pm 3.1 \%$ in the FBG of $<5.55 \mathrm{mmol} / \mathrm{L}$ group, $5.9 \pm 2.8 \%$ in the $5.55-6.05 \mathrm{mmol} / \mathrm{L}$ group, $5.7 \pm 3.1 \%$ in the $6.11-$ $6.94 \mathrm{mmol} / \mathrm{L}$ group, and $5.1 \pm 2.6 \%$ in the $\geq 6.99 \mathrm{mmol} / \mathrm{L}$ or known type 2 diabetes group $(\mathrm{p}<0.001)$. FMD values in the FBG $5.55-$ $6.05 \mathrm{mmol} / \mathrm{L}, 6.11-6.94 \mathrm{mmol} / \mathrm{L}$ and $\geq 6.99 \mathrm{mmol} / \mathrm{L}$ or known diaebtes groups were significantly smaller than the values in the FBG< $5.55 \mathrm{mmol} / \mathrm{L}$ group $(p<0.001$, respectively). FMD values were similar in FBG 5.55-6.05 mmol/L group and 6.11-6.94 mmol/L group ( $p$ $=0.80)$.

The division points for the lowest quartile and second quartile were FMD of $4.2 \%$. Therefore, we defined small FMD as FMD of $<4.2 \%$. We took the FBG of $<5.55 \mathrm{mmol} / \mathrm{L}$ group as a reference for deriving the low quartiles of FMD in the other groups. After adjustments for age over 65 years, gender, presence of hypertension, presence of dyslipidemia, presence of obesity (body mass index $\geq 30 \mathrm{~m}^{2} / \mathrm{kg}$ ), and current smoking, the odds of having the lowest quartile of FMD were significantly higher in the FBG of 5.55-6.05 mmol/L group, 6.11$6.94 \mathrm{mmol} / \mathrm{L}$ group and $\geq 6.99 \mathrm{mmol} / \mathrm{L}$ or known type 2 diabetes group than in the reference group: $5.55-6.05 \mathrm{mmol} / \mathrm{L}$ (OR: 1.26, 95\% Cl: $1.10-1.45), 6.11-6.94 \mathrm{mmol} / \mathrm{L}$ (OR: $1.42,95 \% \mathrm{Cl}: 1.16-1.74)$, and $\geq 6.99 \mathrm{mmol} / \mathrm{L}$ or known type 2 diabetes (OR: 1.37, $95 \%$ Cl: $1.15-$ 1.64) (Table 2).

Table 2

Multivariate Analysis of Relationships among Low Quartiles of FMD and FBG Level

\begin{tabular}{|llll|}
\hline \multicolumn{4}{|c|}{ Odds Ratio (95\% Confidence Interval); P Value } \\
\hline FBG, mmol/L & Unadjusted & Model 1 & Model 2 \\
\hline FBG $<5.55$ & 1 (reference) & 1 (reference) & 1 (reference) \\
\hline FBG $5.55-6.05$ & $1.51(1.32-1.72) ;<0.001$ & $1.40(1.22-1.61) ;<0.001$ & $1.26(1.10-1.45) ; 0.001$ \\
\hline FBG $6.11-6.94$ & $1.86(1.53-2.26) ;<0.001$ & $1.73(1.42-2.10) ;<0.001$ & $1.42(1.16-1.74) ;<0.001$ \\
\hline FBG $\geq 6.99$ or type 2 diabetes & $2.32(1.98-2.73) ;<0.001$ & $1.85(1.56-2.19) ;<0.001$ & $1.37(1.15-1.64) ;<0.001$ \\
\hline Model 1; adjusted for age $\geq 65$ years old, gender. & & \\
\hline $\begin{array}{l}\text { Model 2; adjusted for age } \geq 65 \text { years old, gender, hypertension, dyslipidemia, obesity, current smoking. FMD indicates flow-mediated } \\
\text { vasodilation; FBG, fasting blood glucose; OR, odds ratio; Cl, confidence interval. }\end{array}$ & & \\
\hline
\end{tabular}

\section{FMD values in six groups of FBG levels}

Finally, we divided the patients into six groups based on their FBG levels: $<5.55 \mathrm{mmol} / \mathrm{L}(<5.00 \mathrm{mmol} / \mathrm{L}, 5.00-5.22 \mathrm{mmol} / \mathrm{L}$ and $5.27-$ $5.50 \mathrm{mmol} / \mathrm{L}), 5.55-6.05 \mathrm{mmol} / \mathrm{L}, 6.11-6.94 \mathrm{mmol} / \mathrm{L}$ and $\geq 6.99 \mathrm{mmol} / \mathrm{L}$ or known type 2 diabetes, and assessed their endothelial 
function. There were significant differences in age, gender, body mass index, heart rate, systolic blood pressure, diastolic blood pressure, levels of total cholesterol, triglycerides, high-density lipoprotein cholesterol, low-density lipoprotein cholesterol, creatinine, uric acid, FBG, and $\mathrm{HbA} 1 \mathrm{c}$, prevalences of hypertension, dyslipidemia, and cardiovascular disease, and use of antihypertensive drugs and lipid-lowering drugs among the six groups (Table 3). FMD values were $6.9 \pm 3.1 \%$ in the FBG of $<5.00 \mathrm{mmol} / \mathrm{L} \mathrm{group,} 6.7 \pm 3.1 \%$ in the 5.00 $5.22 \mathrm{mmol} / \mathrm{L}$ group, $6.3 \pm 3.1 \%$ in the $5.27-5.50 \mathrm{mmol} / \mathrm{L}$ group, $5.9 \pm 2.8 \%$ in the $5.55-6.05 \mathrm{mmol} / \mathrm{L}$ group, $5.7 \pm 3.1 \%$ in the $6.11-$ $6.94 \mathrm{mmol} / \mathrm{L}$ group, and $5.1 \pm 2.6 \%$ in the $\geq 6.99 \mathrm{mmol} / \mathrm{L}$ or known type 2 diabetes group $(\mathrm{p}<0.001 ;$ Fig. 3$)$. FMD values were similar in the FBG of < $5.00 \mathrm{mmol} / \mathrm{L}$ group, 5.00-5.22 mmol/L group, 5.55-6.05 mmol/L group and 6.11-6.94 mmol/L group (Fig. 3). 
Table 3

Clinical Characteristics of Patients in Six Groups of FBG Levels

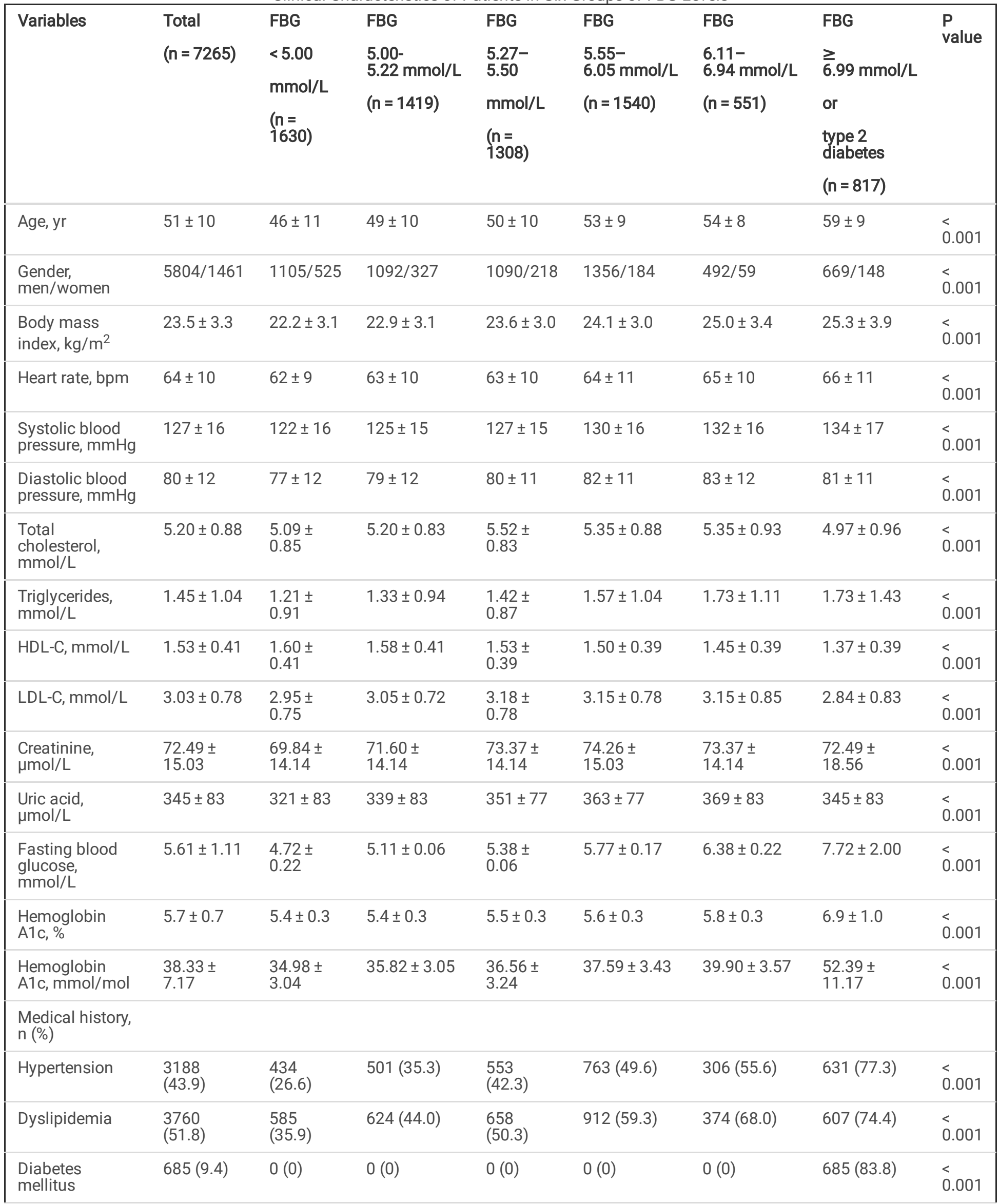

FBG indicates fasting blood glucose; HDL-C, high-density lipoprotein cholesterol; LDL-C, low-density lipoprotein cholesterol; CVD, cardiovascular disease; FMD, flow-mediated vasodilation. 


\begin{tabular}{|c|c|c|c|c|c|c|c|c|}
\hline Variables & $\begin{array}{l}\text { Total } \\
(n=7265)\end{array}$ & $\begin{array}{l}\text { FBG } \\
<5.00 \\
\text { mmol/L } \\
(n= \\
1630)\end{array}$ & $\begin{array}{l}\text { FBG } \\
5.00- \\
5.22 \mathrm{mmol} / \mathrm{L} \\
(n=1419)\end{array}$ & $\begin{array}{l}\text { FBG } \\
5.27- \\
5.50 \\
\mathrm{mmol} / \mathrm{L} \\
(\mathrm{n}= \\
1308)\end{array}$ & $\begin{array}{l}\text { FBG } \\
5.55- \\
6.05 \mathrm{mmol} / \mathrm{L} \\
(\mathrm{n}=1540)\end{array}$ & $\begin{array}{l}\text { FBG } \\
6.11- \\
6.94 \mathrm{mmol} / \mathrm{L} \\
(n=551)\end{array}$ & $\begin{array}{l}\text { FBG } \\
\geq \\
6.99 \mathrm{mmol} / \mathrm{L} \\
\text { or } \\
\text { type } 2 \\
\text { diabetes } \\
(n=817)\end{array}$ & $\begin{array}{l}P \\
\text { value }\end{array}$ \\
\hline CVD, n (\%) & 689 (9.5) & $62(3.8)$ & $68(4.8)$ & $84(6.4)$ & 137 (8.9) & 71 (12.9) & 267 (32.7) & $\begin{array}{l}< \\
0.001\end{array}$ \\
\hline $\begin{array}{l}\text { Current } \\
\text { Smoking, n (\%) }\end{array}$ & $\begin{array}{l}2189 \\
(30.3)\end{array}$ & $\begin{array}{l}523 \\
(32.1)\end{array}$ & $431(30.5)$ & $\begin{array}{l}401 \\
(30.8)\end{array}$ & $456(29.7)$ & $161(29.5)$ & 217 (27.2) & 0.23 \\
\hline \multicolumn{9}{|l|}{$\begin{array}{l}\text { Medication, n } \\
(\%)\end{array}$} \\
\hline $\begin{array}{l}\text { Antihypertensive } \\
\text { drugs }\end{array}$ & $\begin{array}{l}2009 \\
(27.7)\end{array}$ & $\begin{array}{l}217 \\
(13.3)\end{array}$ & $294(20.7)$ & $\begin{array}{l}318 \\
(24.3)\end{array}$ & $480(31.2)$ & $200(36.4)$ & 500 (61.3) & $<.001$ \\
\hline $\begin{array}{l}\text { Lipid lowering } \\
\text { drugs }\end{array}$ & $\begin{array}{l}1116 \\
(15.4)\end{array}$ & $110(6.8)$ & $134(9.5)$ & $\begin{array}{l}158 \\
(12.1)\end{array}$ & $238(15.5)$ & 106 (19.3) & 370 (45.3) & $<.001$ \\
\hline $\begin{array}{l}\text { Anti-diabetic } \\
\text { drugs }\end{array}$ & 489 (6.7) & $0(0)$ & $0(0)$ & $0(0)$ & $0(0)$ & $0(0)$ & $489(60.0)$ & $<.001$ \\
\hline
\end{tabular}

We took the FBG of $<5.00 \mathrm{mmol} / \mathrm{L}$ group as a reference and for deriving for the low quartiles of FMD in the other groups. After adjustments for confounding factors, the odds of having lowest quartile of FMD were significantly higher in FBG of 5.27-5.50 mmol/L group, 5.55-6.05 mmol/L group, $6.11-6.94 \mathrm{mmol} / \mathrm{L}$ group and $\geq 6.99 \mathrm{mmol} / \mathrm{L}$ or known type 2 diabetes group than in the reference group: $5.27-5.50 \mathrm{mmol} / \mathrm{L}$ group (OR: 1.28, 95\% Cl: 1.07-1.55), 5.55-6.05 mmol/L (OR: 1.41, 95\% Cl: 1.18-1.68), 6.11-6.94 mmol/L (OR: $1.59,95 \% \mathrm{Cl}: 1.26-2.01$ ), and $\geq 6.99 \mathrm{mmol} / \mathrm{L}$ or known type 2 diabetes (OR: 1.54, 95\% Cl: 1.25-1.90). The odds of having the lowest quartile of FMD in subjects with FBG of $<5.00 \mathrm{mmol} / \mathrm{L}$ and subjects with FBG of $5.00-5.22 \mathrm{mmol} / \mathrm{L}$ were similar (OR: 1.07, 95\% Cl: 0.89-1.29) (Table 4).

Table 4

Multivariate Analysis of Relationships among Low Quartiles of FMD and FBG Level

\section{Odds Ratio (95\% Confidence Interval); P Value}

\begin{tabular}{llll} 
FBG, $\mathrm{mmol} / \mathrm{L}$ & Unadjusted & Model 1 & Model 2 \\
\hline FBG $<5.00$ & 1 (reference) & 1 (reference) & 1 (reference) \\
\hline FBG $5.00-5.22$ & $1.19(0.99-1.43) ; 0.06$ & $1.15(0.96-1.39) ; 0.13$ & $1.07(0.89-1.29) ; 0.46$ \\
\hline FBG 5.27-5.50 & $1.52(1.27-1.82) ;<0.001$ & $1.43(1.19-1.72) ;<0.001$ & $1.28(1.07-1.55) ; 0.01$ \\
\hline FBG 5.55-6.05 & $1.82(1.54-2.16) ;<0.001$ & $1.66(1.39-1.97) ;<0.001$ & $1.41(1.18-1.68) ;<0.001$ \\
\hline FBG $6.11-6.94$ & $2.25(1.81-2.81) ;<0.001$ & $2.04(1.63-2.56) ;<0.001$ & $1.59(1.26-2.01) ;<0.001$ \\
\hline FBG $\geq 6.99$ or type 2 diabetes & $2.82(2.32-3.40) ;<0.001$ & $2.19(1.79-2.67) ;<0.001$ & $1.54(1.25-1.91) ;<0.001$
\end{tabular}

Model 1; adjusted for age $\geq 65$ years old, gender.

Model 2; adjusted for age $\geq 65$ years old, gender, hypertension, dyslipidemia, obesity, current smoking. FMD indicates flow-mediated vasodilation; FBG, fasting blood glucose; OR, odds ratio; $\mathrm{Cl}$, confidence interval.

Low quartile of FMD indicates less than $4.2 \%$. 
In the present study, we demonstrated that FBG was an independent predictor of FMD, that FMD was similarly impaired in the FBG of 5.55-6.05 mmol/L and 6.11-6.94 mmol/L group compared with that in the FBG of $<5.55 \mathrm{mmol} / \mathrm{L}$ group, and that after adjustments for confounding factors, FMD values in the FBG of $5.55-6.05 \mathrm{mmol} / \mathrm{L}$ group, $6.11-6.94 \mathrm{mmol} / \mathrm{L}$ group, and $\geq 6.99 \mathrm{mmol} / \mathrm{L}$ or known type 2 diabetes group were significantly smaller than the value in the FBG of $<5.55 \mathrm{mmol} / \mathrm{L}$ group. We also demonstrated for the first time that FMD was significantly smaller in the FBG of $5.27-5.50 \mathrm{mmol} / \mathrm{L}$ group than in the $F B G$ of $<5.00 \mathrm{mmol} / \mathrm{L}$ group.

First, to evaluate the relationships between FBG levels and endothelial function in more detail, we divided the subjects into four groups of FBG levels. Endothelial function was similarly impaired in the FBG of 5.55-6.05 mmol/L group and in the FBG of $6.11-6.94 \mathrm{mmol} / \mathrm{L}$ group compared with that in the FBG of $<5.55 \mathrm{mmol} / \mathrm{L}$ group. Previous studies showing that subjects in an FBG of $5.55-6.94 \mathrm{mmol} / \mathrm{L}$ group and FBG of $6.11-6.94 \mathrm{mmol} / \mathrm{L}$ group have endothelial dysfunction support our findings. $[15-18,23]$ These finding suggest that FBG of $\geq 5.55 \mathrm{mmol} / \mathrm{L}$ is a risk factor of endothelial dysfunction. In 2003, ADA proposed that the lower limit of IFG should be lowered from $6.11 \mathrm{mmol} / \mathrm{L}$ to $5.55 \mathrm{mmol} / \mathrm{L}$ since an IFG cut-off value of $5.55 \mathrm{mmol} / \mathrm{L}$ is better than an IFG cut-off value of $6.11 \mathrm{mmol} / \mathrm{L}$ for predicting future type 2 diabetes onset.[24] From the aspect of vascular function, endothelial function in subjects with FBG of 5.55$6.05 \mathrm{mmol} / \mathrm{L}$ was similarly impaired in the FBG of $6.11-6.94 \mathrm{mmol} / \mathrm{L}$ group.

Next, there is no information on from what level of FBG adversely affects endothelial function. Therefore, we divided FBG of < $5.55 \mathrm{mmol} / \mathrm{L}$, which was previously classified as normal blood glucose, into the three groups, FBG of $<5.00 \mathrm{mmol} / \mathrm{L}$, FBG of 5.00 $5.22 \mathrm{mmol} / \mathrm{L}$ and FBG of $5.27-5.50 \mathrm{mmol} / \mathrm{L}$, and evaluated the relationships between FBG levels of $<5.00 \mathrm{mmol} / \mathrm{L}, 5.00-5.22 \mathrm{mmol} / \mathrm{L}$, $5.27-5.50 \mathrm{mmol} / \mathrm{L}, 5.55-6.05 \mathrm{mmol} / \mathrm{L}, 6.11-6.94 \mathrm{mmol} / \mathrm{L}$ and $\geq 6.99 \mathrm{mmol} / \mathrm{L}$ or known type 2 diabetes and FMD. In the present study, the odds of having the lowest quartile of FMD was significantly higher in the FBG of $5.27-5.50 \mathrm{mmol} / \mathrm{L}$ group than in the FBG of < $5.00 \mathrm{mmol} / \mathrm{L}$ group. A pre-IFG state, FBG of $5.27-5.50 \mathrm{mmol} / \mathrm{L}$, was also associated with endothelial dysfunction. It is likely that endothelial function is almost simultaneously impaired when FBG level increases over $5.27 \mathrm{mmol} / \mathrm{L}$, while it is unclear whether the association of elevation of FBG with the existence of endothelial dysfunction is a cause or consequence.

It is thought that the mechanisms by which hyperglycemia impairs endothelial function are increases in oxidative stress and inflammation. Hyperglycemia-induced increase in reactive oxygen species plays a critical role in oxidative stress through the several pathways including overproduction of mitochondria-derive superoxide anion, polyol pathway, advanced glycation end-products/receptor for advanced glycation end-products pathway, protein kinas C pathway and hexosamine pathway, leading to a decrease in nitric oxide bioavailability and resulting in endothelial dysfunction.[25-29] Hyperglycemia involves not only a high blood glucose state but also metabolic disorders including obesity, dyslipidemia, insulin resistance and hypertension. Under the condition of hyperglycemia, obesityinduced hypertrophic adipocytes produce inflammatory cytokines such as tumor necrosis factor-a and interleukin- 6 and reduce antiinflammatory cytokine adiponectin, leading to an increase in inflammation and resulting in endothelial dysfunction. It is well known that hypertension and dyslipidemia induce increases in oxidative stress and inflammation.[30-32] Oxidative stress and inflammation make a vicious circle and contribute to endothelial dysfunction.[33] In the present study, we found associations of FBS with obesity and with increases in blood pressure and low-density lipoprotein level. FMD decreased in relation to an increase in FBG, and FBG was an independent predictor of FMD.

\section{Study Limitations}

This study has some limitations. First, although this study was conducted by multiple centers (31 institutes) and using a large sample size, this study was a cross-sectional study. Therefore, we were able to evaluate the association but not causality between FBG level and FMD. Second, we did not have information on results of 75-gram oral glucose tolerance tests. Therefore, we could not obtain data on impaired glucose tolerance (IGT). Previous studies have shown that IGT is a predictor of cardiovascular events and that it is potentially a better predictor than IFG of cardiovascular events[34], while it is controversial whether IFG is an independent predictor of cardiovascular events.[34, 35] In the present study, we clearly showed that endothelial function is impaired not only in subjects with IFG but also even in subjects with pre-IFG. Third, this study was conducted in Japan. It is well known that insulin sensitivity is lower in Asians including Japanese than in Caucasians and that Asians are more likely to have an increased risk of diabetes. [36] We cannot deny the possibility that our results are not applicable to other races. Finally, unfortunately, the FMD-J database did not include data on chemical biomarkers of oxidative stress and inflammation. Measurements of oxidative stress and inflammation markers would enable more specific conclusions concerning the role of FBG in endothelial function to be drawn.

\section{Conclusions}


In conclusion, high normal blood glucose of $5.27-5.50 \mathrm{mmol} / \mathrm{L}$ as well as FBG of $6.11-6.94 \mathrm{~mol} / \mathrm{L}$ was associated with endothelial dysfunction. Endothelial dysfunction may begin from FBG of $5.27-5.50 \mathrm{mmol} / \mathrm{L}$, a so-called pre-IFG state. It is thought that intensive lifestyle modification or pharmacological intervention is needed to decrease FBG in individuals with pre-IFG who have FBG of more than $5.27 \mathrm{mmol} / \mathrm{L}$.

\section{Abbreviations}

FBG

fasting blood glucose

FMD

flow-mediated vasodilation

HbA1c

hemoglobin A1C

HDL-C

high-density lipoprotein cholesterol

IFG

impaired fasting glucose

LDL-C

low-density lipoprotein cholesterol

\section{Declarations}

\section{Ethics approval and consent to participate}

The ethical committees of the participating institutions approved the study protocol. All participants provide written informed consent before date collection. The protocol was registered in the University Hospital Medical Information Network Clinical Trials Registry

(UMIN000012950, UMIN000012951, UMIN000012952, and UMIN000003409)

\section{Consent for publication}

Not applicable

\section{Availability of date and material}

Not applicable

\section{Competing interests}

The authors declared that they do not have anything to disclose regarding conflict of interest with respect to this manuscript

\section{Funding sources}

Grant-in-Aid for Scientific Research from the Ministry of Education, Science and Culture of Japan (18590815 and 21590898 to Y.Higashi) and a Grant-in-Aid of Japanese Arteriosclerosis Prevention Fund (to Y.Higashi).

\section{Author's contributions}

T.Y. and Y.Higashi, drafting the article and conception of the study; T.H., Y.Hashimoto, Y.T., M.K., Y.Han, T.M., S.K., T.H., C.G., Y.A., A.N., and F.M.Y. acquiring subjects and/or data; E.H., K.C. and Y.K., revising the article critically for important intellectual content. Y.Higashi is the guarantor of this work and, as such, had full access to all of the data in the study and takes responsibility for the integrity of the data and the accuracy of data analysis.

\section{Acknowledgments}

The authors would like to thank all of the patients who participated in this study. In addition, we thank Miki Kumiji, Megumi Wakisaka, Kiichiro Kawano and Satoko Michiyama for their excellent secretarial assistance; FMD-J investigators Takayuki Hidaka, MD, PhD; Shuji 
Nakamura, MD, PhD; Junko Soga, MD, PhD; Yuichi Fujii, MD, PhD; Naomi Idei, MD; Noritaka Fujimura, MD, PhD; Shinsuke Mikami, MD, PhD; Yumiko Iwamoto, MD; Akimichi Iwamoto, MD, PhD; Takeshi Matsumoto, MD, PhD; Nozomu Oda, MD, PhD (Department of Cardiovascular Medicine, Hiroshima University Graduate School of Biomedical Sciences, Hiroshima, Japan); Kana Kanai, PhD; Haruka Morimoto, PhD (Department of Cardiovascular Regeneration and Medicine, Research Institute for Radiation Biology and Medicine, Hiroshima University, Hiroshima, Japan); Tomohisa Sakashita, MD, PhD; Yoshiki Kudo, MD, PhD (Department of Obstetrics and Gynecology, Hiroshima University Graduate School of Biomedical Sciences, Hiroshima, Japan); Taijiro Sueda, MD, PhD (Department of Surgery, Hiroshima University Graduate School of Biomedical Sciences, Hiroshima, Japan); Hirofumi Tomiyama, MD, PhD, FAHA; Akira Yamashina, MD, PhD (Department of Cardiology, Tokyo Medical University, Tokyo, Japan); Bonpei Takase, MD, PhD, FAHA (Division of Biomedical Engineering, National Defense Medical College Research Institute, Tokorozawa, Japan); Takahide Kohro, MD, PhD (Department of Cardiology, Tokyo Medical University, Tokyo, Japan); Toru Suzuki, MD, PhD (Cardiovascular Medicine, University of Leicester, Leicester, UK); Tomoko Ishizu, MD, PhD (Cardiovascular Division, Institute of Clinical Medicine, University of Tsukuba, Ibaraki, Japan); Shinichiro Ueda, MD, PhD (Department of Clinical Pharmacology and Therapeutics, University of the Ryukyu School of Medicine, Okinawa, Japan); Tsutomu Yamazaki, MD, PhD (Clinical Research Support Center, Faculty of Medicine, The University of Tokyo, Tokyo, Japan); Tomoo Furumoto, MD, PhD (Department of Cardiovascular Medicine, Hokkaido University Graduate School of Medicine, Hokkaido, Japan); Kazuomi Kario, MD, PhD (Division of Cardiovascular Medicine, Jichi Medical University School of Medicine, Tochigi, Japan); Teruo Inoue, MD, PhD (Department of Cardiovascular Medicine, Dokkyo Medical University, Mibu, Tochigi, Japan); Shinji Koba, MD, PhD (Department of Medicine, Division of Cardiology, Showa University School of Medicine, Tokyo, Japan); Kentaro Watanabe, MD, PhD (Department of Neurology, Hematology, Metaboism, Endocrinology and Diabetology (DNHMED), Yamagata University School of Medicine, Yamagata, Japan); Yasuhiko Takemoto, MD, PhD (Department of Internal Medicine and Cardiology, Osaka City University Graduate School of Medicine, Osaka, Japan); Takuzo Hano, MD, PhD (Department of Medical Education and Population-based Medicine, Postgraduate School of Medicine, Wakayama Medical University, Wakayama, Japan); Masataka Sata, MD, PhD (Department of Cardiovascular Medicine, Institute of Health Biosciences, The University of Tokushima Graduate School, Tokushima, Japan); Yutaka Ishibashi, MD, PhD (Department of General Medicine, Shimane University Faculty of Medicine, Izumo, Japan); Koichi Node, MD, PhD (Department of Cardiovascular and Renal Medicine, Saga University, Saga, Japan); Koji Maemura, MD, PhD (Department of Cardiovascular Medicine, Nagasaki University Graduate School of Biomedical Sciences, Nagasaki, Japan); Yusuke Ohya, MD, PhD (The Third Department of Internal Medicine, University of the Ryukyus, Okinawa, Japan); Taiji Furukawa, MD, PhD (Department of Internal Medicine, Teikyo University School of Medicine, Tokyo, Japan); Hiroshi Ito, MD, PhD (Department of Cardiovascular Medicine, Okayama University Graduate School of Medicine, Dentistry and Pharmaceutical Sciences, Japan); and Hisao Ikeda, MD, PhD (Faculty of Fukuoka Medical Technology, Teikyo University, Omuta, Japan).

\section{References}

1. Standl E, Balletshofer B, Dahl B, Weichenhain B, Stiegler H, Hormann A, Holle R. Predictors of 10-year macrovascular and overall mortality in patients with NIDDM: the Munich General Practitioner Project. Diabetologia. 1996;39(12):1540-5.

2. Haffner SM, Stern MP, Hazuda HP, Mitchell BD, Patterson JK. Cardiovascular risk factors in confirmed prediabetic individuals. Does the clock for coronary heart disease start ticking before the onset of clinical diabetes? Jama 1990, 263(21):2893-2898.

3. 2. Classification and Diagnosis of Diabetes: Standards of Medical Care in Diabetes-2019. Diabetes Care 2019, 42(Suppl 1):S13-s28.

4. Haneda M, Noda M, Origasa H, Noto H, Yabe D, Fujita Y, Goto A, Kondo T, Araki E. Japanese Clinical Practice Guideline for Diabetes 2016. Diabetol Int. 2018;9(1):1-45.

5. Ross R. Atherosclerosis-an inflammatory disease. N Engl J Med. 1999;340(2):115-26.

6. Higashi Y, Noma K, Yoshizumi M, Kihara Y. Endothelial function and oxidative stress in cardiovascular diseases. Circulation journal: official journal of the Japanese Circulation Society. 2009;73(3):411-8.

7. Modena MG, Bonetti L, Coppi F, Bursi F, Rossi R. Prognostic role of reversible endothelial dysfunction in hypertensive postmenopausal women. J Am Coll Cardiol. 2002;40(3):505-10.

8. Gokce N, Keaney JF Jr, Hunter LM, Watkins MT, Menzoian JO, Vita JA. Risk stratification for postoperative cardiovascular events via noninvasive assessment of endothelial function: a prospective study. Circulation. 2002;105(13):1567-72.

Page $12 / 16$ 
9. Brevetti G, Silvestro A, Schiano V, Chiariello M. Endothelial dysfunction and cardiovascular risk prediction in peripheral arterial disease: additive value of flow-mediated dilation to ankle-brachial pressure index. Circulation. 2003;108(17):2093-8.

10. Lerman A, Zeiher AM. Endothelial function: cardiac events. Circulation. 2005;111(3):363-8.

11. Yeboah J, Folsom AR, Burke GL, Johnson C, Polak JF, Post W, Lima JA, Crouse JR, Herrington DM. Predictive value of brachial flowmediated dilation for incident cardiovascular events in a population-based study: the multi-ethnic study of atherosclerosis. Circulation. 2009;120(6):502-9.

12. Maruhashi T, Soga J, Fujimura N, Idei N, Mikami S, Iwamoto Y, Kajikawa M, Matsumoto T, Hidaka T, Kihara Y, et al. Relationship between flow-mediated vasodilation and cardiovascular risk factors in a large community-based study. Heart. 2013;99(24):183742.

13. Henry RM, Ferreira I, Kostense PJ, Dekker JM, Nijpels G, Heine RJ, Kamp O, Bouter LM, Stehouwer CD. Type 2 diabetes is associated with impaired endothelium-dependent, flow-mediated dilation, but impaired glucose metabolism is not; The Hoorn Study. Atherosclerosis. 2004;174(1):49-56.

14. Williams SB, Cusco JA, Roddy MA, Johnstone MT, Creager MA. Impaired nitric oxide-mediated vasodilation in patients with noninsulin-dependent diabetes mellitus. J Am Coll Cardiol. 1996;27(3):567-74.

15. Vehkavaara S, Seppala-Lindroos A, Westerbacka J, Groop PH, Yki-Jarvinen H. In vivo endothelial dysfunction characterizes patients with impaired fasting glucose. Diabetes Care. 1999;22(12):2055-60.

16. Xiang GD, Wang YL. Regular aerobic exercise training improves endothelium-dependent arterial dilation in patients with impaired fasting glucose. Diabetes Care. 2004;27(3):801-2.

17. Rodriguez CJ, Miyake Y, Grahame-Clarke C, Di Tullio MR, Sciacca RR, Boden-Albala B, Sacco RL, Homma S. Relation of plasma glucose and endothelial function in a population-based multiethnic sample of subjects without diabetes mellitus. Am $\mathrm{J}$ Cardiol. 2005;96(9):1273-7.

18. Su Y, Liu XM, Sun YM, Wang YY, Luan Y, Wu Y. Endothelial dysfunction in impaired fasting glycemia, impaired glucose tolerance, and type 2 diabetes mellitus. Am J Cardiol. 2008;102(4):497-8.

19. Tomiyama H, Kohro T, Higashi Y, Takase B, Suzuki T, Ishizu T, Ueda S, Yamazaki T, Furumoto T, Kario K, et al. A multicenter study design to assess the clinical usefulness of semi-automatic measurement of flow-mediated vasodilatation of the brachial artery. Int Heart J. 2012;53(3):170-5.

20. Executive Summary of The Third Report of The National Cholesterol Education Program (NCEP) Expert Panel on Detection, Evaluation, And Treatment of High Blood Cholesterol In Adults (Adult Treatment Panel III). Jama 2001, 285(19):2486-2497.

21. American Diabetes Association. : clinical practice recommendations 1999. Diabetes Care. 1999;22(Suppl 1):1-114.

22. Maruhashi T, Soga J, Fujimura N, Idei N, Mikami S, Iwamoto Y, Kajikawa M, Matsumoto T, Hidaka T, Kihara Y, et al. Nitroglycerineinduced vasodilation for assessment of vascular function: a comparison with flow-mediated vasodilation. Arterioscler Thromb Vasc Biol. 2013;33(6):1401-8.

23. Diehl KJ, Templeton DL, Ma J, Weil BR, Greiner JJ, Stauffer BL, DeSouza CA. Impaired fasting blood glucose is associated with increased endothelin-1 vasoconstrictor tone. Atherosclerosis. 2013;229(1):130-3.

24. Genuth S, Alberti KG, Bennett P, Buse J, Defronzo R, Kahn R, Kitzmiller J, Knowler WC, Lebovitz H, Lernmark A, et al. Follow-up report on the diagnosis of diabetes mellitus. Diabetes Care. 2003;26(11):3160-7.

25. Brownlee M. Biochemistry and molecular cell biology of diabetic complications. Nature. 2001;414(6865):813-20.

26. Du XL, Edelstein D, Rossetti L, Fantus IG, Goldberg H, Ziyadeh F, Wu J, Brownlee M. Hyperglycemia-induced mitochondrial superoxide overproduction activates the hexosamine pathway and induces plasminogen activator inhibitor-1 expression by increasing Sp1 glycosylation. Proc Natl Acad Sci U S A. 2000;97(22):12222-6.

27. Koya D, King GL. Protein kinase C activation and the development of diabetic complications. Diabetes. 1998;47(6):859-66.

28. Kolm-Litty V, Sauer U, Nerlich A, Lehmann R, Schleicher ED. High glucose-induced transforming growth factor beta1 production is mediated by the hexosamine pathway in porcine glomerular mesangial cells. J Clin Invest. 1998;101(1):160-9.

29. Stirban A, Negrean M, Stratmann B, Gawlowski T, Horstmann T, Götting C, Kleesiek K, Mueller-Roesel M, Koschinsky T, Uribarri J, et al. Benfotiamine prevents macro- and microvascular endothelial dysfunction and oxidative stress following a meal rich in advanced glycation end products in individuals with type 2 diabetes. Diabetes Care. 2006;29(9):2064-71.

30. Aroor AR, McKarns S, Demarco VG, Jia G, Sowers JR. Maladaptive immune and inflammatory pathways lead to cardiovascular insulin resistance. Metabolism. 2013;62(11):1543-52.

Page $13 / 16$ 
31. Supriya R, Tam BT, Yu AP, Lee PH, Lai CW, Cheng KK, Yau SY, Chan LW, Yung BY, Sheridan S, et al. Adipokines demonstrate the interacting influence of central obesity with other cardiometabolic risk factors of metabolic syndrome in Hong Kong Chinese adults. PLoS One. 2018;13(8):e0201585.

32. Després JP, Lemieux I. Abdominal obesity and metabolic syndrome. Nature. 2006;444(7121):881-7.

33. Cai H, Harrison DG. Endothelial dysfunction in cardiovascular diseases: the role of oxidant stress. Circ Res. 2000;87(10):840-4.

34. Tominaga M, Eguchi H, Manaka H, Igarashi K, Kato T, Sekikawa A. Impaired glucose tolerance is a risk factor for cardiovascular disease, but not impaired fasting glucose. The Funagata Diabetes Study. Diabetes Care. 1999;22(6):920-4.

35. Doi Y, Ninomiya T, Hata J, Fukuhara M, Yonemoto K, Iwase M, lida M, Kiyohara Y. Impact of glucose tolerance status on development of ischemic stroke and coronary heart disease in a general Japanese population: the Hisayama study. Stroke. 2010;41(2):203-9.

36. Kodama K, Tojjar D, Yamada S, Toda K, Patel CJ, Butte AJ. Ethnic differences in the relationship between insulin sensitivity and insulin response: a systematic review and meta-analysis. Diabetes Care. 2013;36(6):1789-96.

\section{Figures}

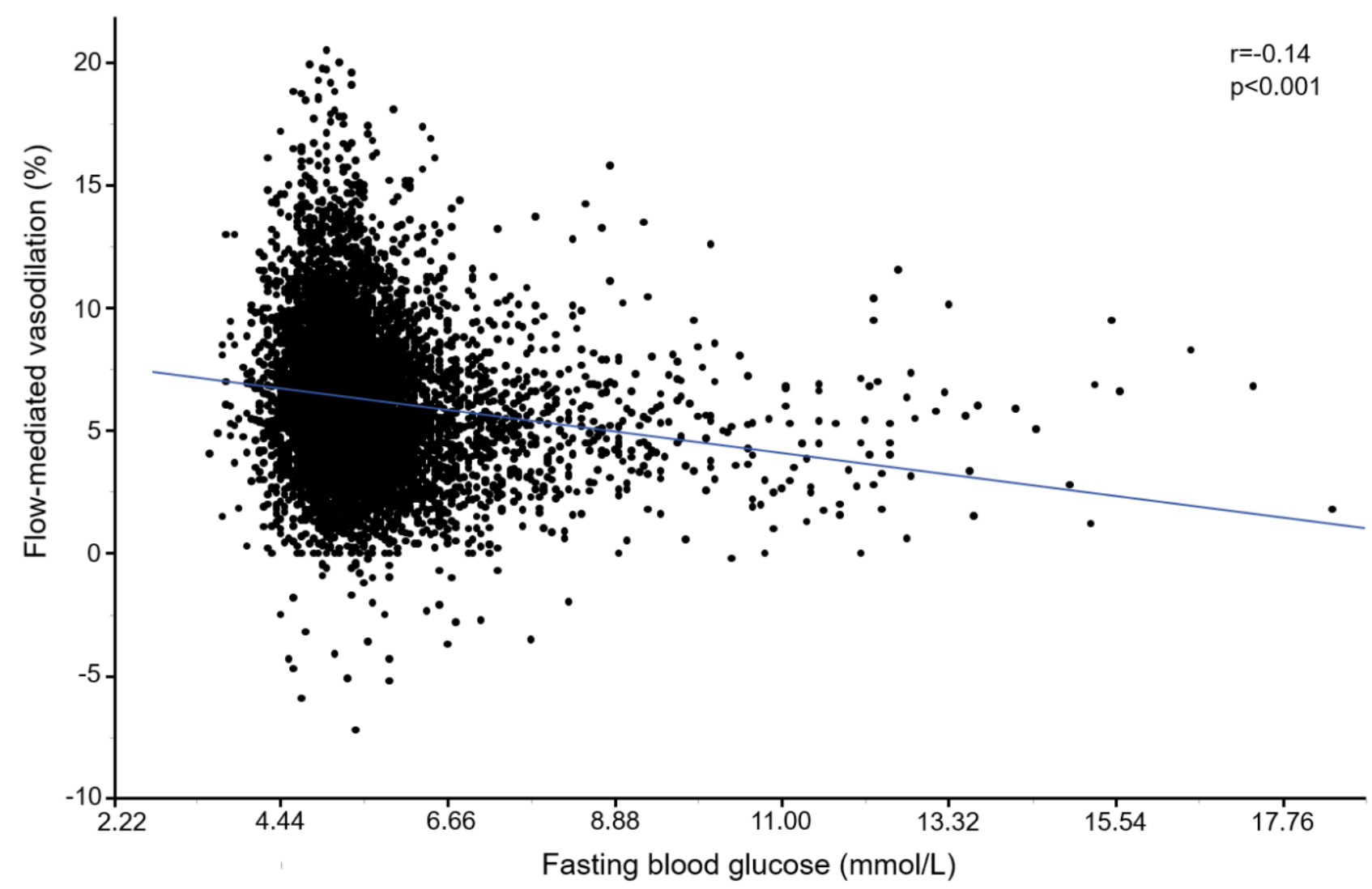

\section{Figure 1}

Scatter plots shows relationship between fasting blood glucose and flow-mediated vasodilation. 


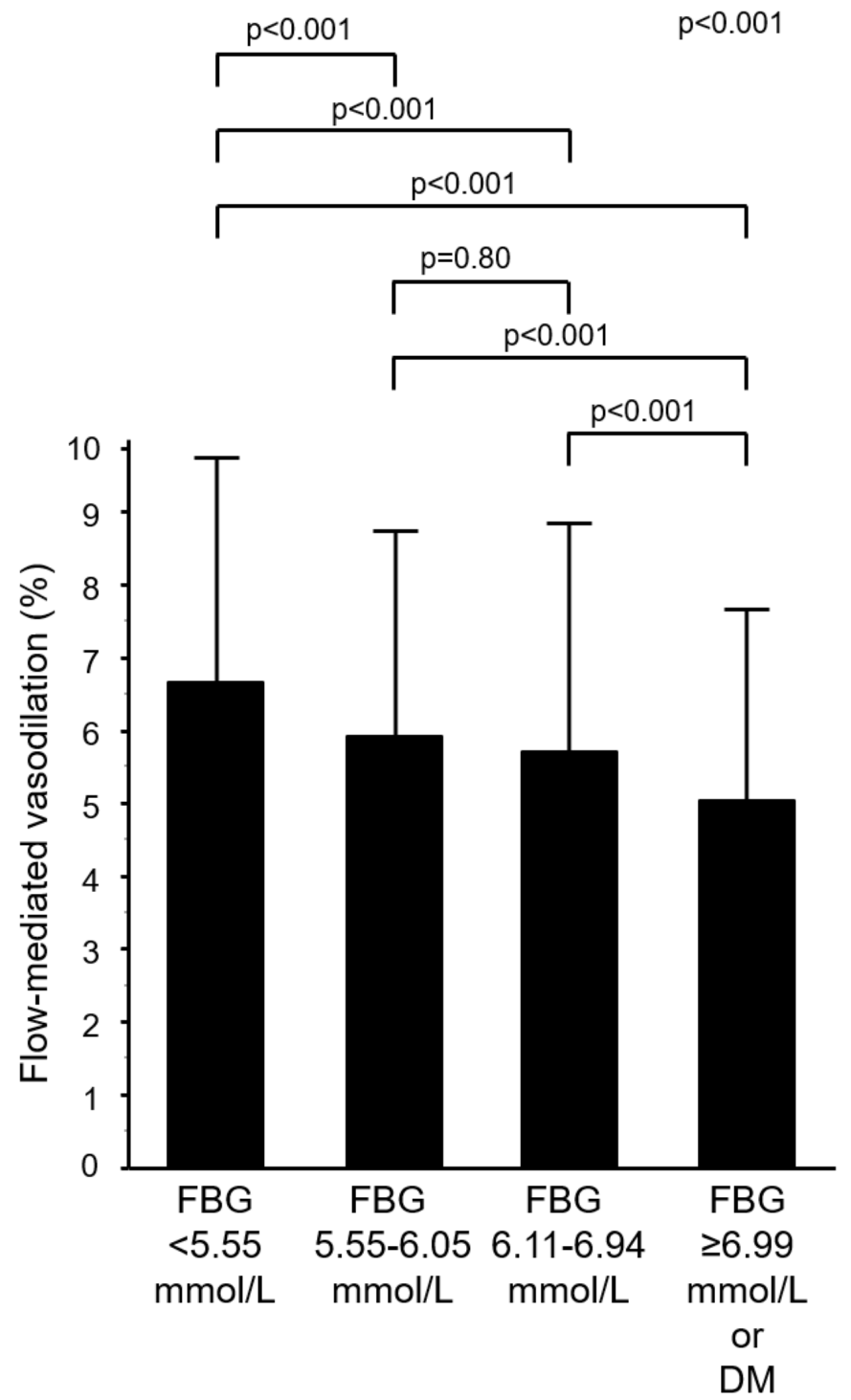

Figure 2

Bar graphs show flow-mediated vasodilation in subjects with FBG of $<5.55 \mathrm{mmol} / \mathrm{L}, 5.55-6.05 \mathrm{mmol} / \mathrm{L}, 6.11-6.94 \mathrm{mmol} / \mathrm{L}$, and $\geq 6.99$ $\mathrm{mmol} / \mathrm{L}$ or known type 2 diabetes. 


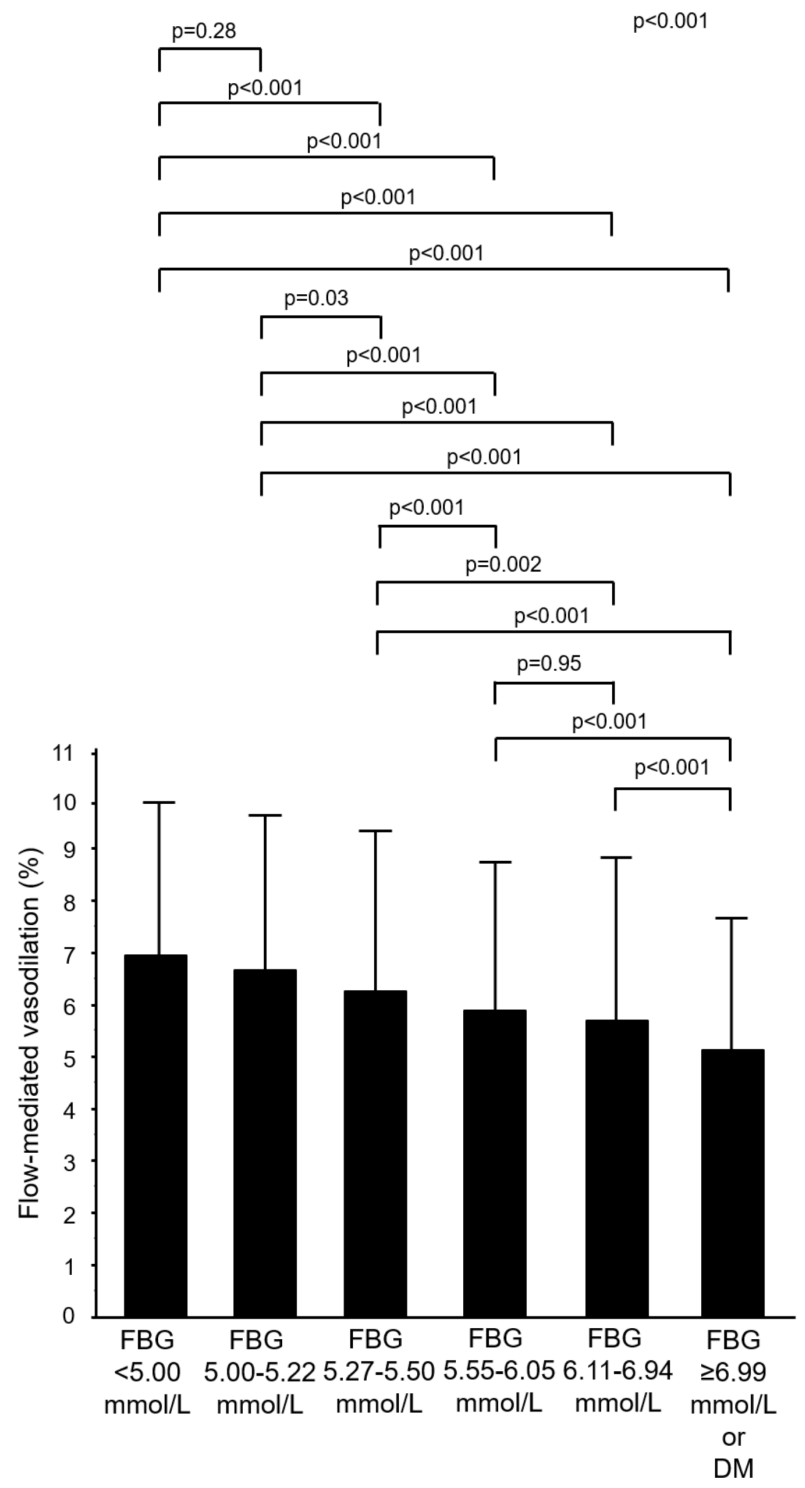

\section{Figure 3}

Bar graphs show flow-mediated vasodilation in subjects with FBG of $<5$. Bar graphs show flow-mediated vasodilation in subjects with FBG of $<5.00 \mathrm{mmol} / \mathrm{L}, 5.00-5.22 \mathrm{mmol} / \mathrm{L}, 5.27-5.50 \mathrm{mmol} / \mathrm{L}, 5.55-6.05 \mathrm{mmol} / \mathrm{L}, 6.11-6.94 \mathrm{mmol} / \mathrm{L}$, and $\geq 6.99 \mathrm{mmol} / \mathrm{L}$ or known type 2 diabetes. 